Article

\title{
Streptococcus pneumoniae Nasopharyngeal Carriage among PCV-10-Vaccinated HIV-1-Infected Children with Maintained Serological Memory in Ethiopia
}

\author{
Mahlet Lemma ${ }^{1,2,3}$, Yonas Bekele ${ }^{1}$, Stefan Petkov ${ }^{1}$, Moa Hägglund ${ }^{4}$, Beyene Petros ${ }^{3}$, \\ Abraham Aseffa ${ }^{2}$ (D), Rawleigh Howe ${ }^{2}$ and Francesca Chiodi ${ }^{1, *}$ \\ 1 Department of Microbiology, Tumor and Cell Biology, Biomedicum, Karolinska Institutet, Solnavägen 9, \\ 17165 Solna, Sweden; mahlet.lemma@ki.se (M.L.); yonas.feyissa@nih.gov (Y.B.); stefan.petkov@ki.se (S.P.) \\ 2 Armauer Hansen Research Institute, Jimma Road, ALERT compound P.O. Box 1005, Addis Ababa, Ethiopia; \\ abraham.aseffa@ahri.gov.et (A.A.); rawleigh.howe@ahri.gov.et (R.H.) \\ 3 Department of Microbial, Cellular and Molecular Biology, Addis Ababa University, Arat Kilo Campus, \\ Addis Ababa, Ethiopia; abule2002@yahoo.com \\ 4 Science for Life Laboratory, Department of Microbiology, Tumor and Cell Biology, Karolinska Institutet, \\ 17165 Solna, Sweden; moa.hagglund@scilifelab.se \\ * Correspondence: francesca.chiodi@ki.se
}

Received: 13 January 2020; Accepted: 23 February 2020; Published: 25 February 2020

\begin{abstract}
Streptococcus pneumoniae (S. pneumoniae) vaccines have substantially reduced the burden of invasive pneumococcal diseases (IPDs) worldwide. Despite high coverage with S. pneumoniae vaccination, upper-respiratory-tract colonization by $S$. pneumoniae is still common. We assessed maintenance of serological responses to $S$. pneumoniae serotypes included in PCV-10 by ELISA in HIV-1-infected children $(\mathrm{n}=50)$ and age-matched controls $(\mathrm{n}=50)$ in Ethiopia. We isolated S. pneumoniae in nasopharyngeal swabs and determined S. pneumoniae serotype by whole genome sequencing (WGS). Comparable levels of S. pneumoniae serotype-specific IgG concentrations were detected in plasma of HIV-1-infected children and matched controls, with geometric mean concentrations (GMCs) consistently higher than the protective threshold for PCV-10 serotypes of $0.35 \mu \mathrm{g} / \mathrm{mL}$. We isolated S. pneumoniae from 38 (out of 97) nasopharyngeal swabs, 25 from HIV-1-infected children and 13 from controls. WGS based serotyping revealed 22 known S. pneumoniae serotypes and 2 nontypeable (NT) isolates. Non-PCV-10 serotypes represented $>90 \%$ of isolates. We showed that HIV-1-infected children and matched controls in Ethiopia carry a level of maintained serological memory to PCV-10 considered protective for IPDs. We identified a higher proportion of nasopharyngeal carriage with highly pathogenic S. pneumoniae non-PCV strains among HIV-1-infected children compared to controls.
\end{abstract}

Keywords: S. pneumoniae; PCV-10; serological memory; nasopharyngeal carriage; whole-genome sequence; HIV-1; children

\section{Introduction}

Streptococcus pneumoniae (S. pneumoniae), although part of the normal flora in the upper respiratory tract, can cause severe noninvasive (pneumonia, sinusitis, otitis) and invasive (bacteremia and meningitis) diseases [1,2]. Based on the variability of capsular antigens, more than 90 serotypes have been described [3]; among these are opportunistic pathogens which can cause different noninvasive and invasive pneumococcal diseases (IPD). Colonization of the upper respiratory tract is the initial step for all forms of pneumococcal disease, and the rate of colonization is higher at an early age [4]. Asymptomatic carriers can easily transmit the bacteria through respiratory droplets to healthy individuals [2]. Age, genetics, comorbidity, socio-economic status and seasons are some of the risk factors for pneumococcal 
diseases [5]. The risk of IPD and community-acquired pneumonia (CAP) was significantly increased during HIV-1 infection and in individuals less than 5 years and older than 65 years of age [6-8]. In 2017, S. pneumoniae was classified as one of the 12 priority pathogens [9].

Pneumococcal diseases are a major public health problem, particularly in low- and middle- income countries where 3.7 million invasive pneumococcal diseases were estimated to occur in 2015 with 318,000 fatal cases in children under the age of five years [10,11]. In Ethiopia, 15,000 pneumococcus related annual deaths occurred in 2015, which makes Ethiopia one of the five countries with the highest rate of pneumonia-related deceases [12]. Of the total deaths related to pneumococcal pneumonia in the African continent (137,000 cases) in 2015, approximately 10\% occurred in HIV-1-infected children [10]. The details on the current impact of S. pneumoniae infection on IPDs in Ethiopia are missing and additional, well-designed studies are urgently needed to evaluate the burden assessment of IPDs in Ethiopia.

Pneumococcal vaccines substantially reduced the burden of IPD in HIV-1-infected individuals [13]; currently, both unconjugated (PPV) and conjugated (PCV) vaccines are available in various dosages against S. pneumoniae infection. The first vaccine, which has been available since 1983, is the pneumococcal polysaccharide vaccine including 23 serotypes, PPV-23 [14]. PPV-23 contains purified pneumococcal polysaccharides and has been shown to elicit protective $\mathrm{T}$ cell-independent $\mathrm{B}$ cell responses against S. pneumoniae in children older than two years of age and in adults [15]. Unfortunately, this polysaccharide vaccine was unable to induce protective immune responses in children under the age of two whose immune system could not yet elicit $\mathrm{T}$ cell-independent responses; these observations suggested the need for the development of other vaccine types for the age range 0-2 years [14,15]. Antibodies against capsular antigens are produced through short-lived humoral immunity; coupling capsular antigens with carrier proteins increased the immunogenicity and longevity of the response [16]. Marginal zone (MZ) B cells, which develop in the absence of germinal center formation, are involved in the response to S. pneumoniae capsular antigens; these cells, whose development is not fully completed before two years of age, can migrate and expand in response to capsular antigens and T cell-independent vaccines [17].

A three-dose schedule of protein-conjugated pneumococcal vaccines (PCV7/10/13) has been shown to induce protective immune responses in vaccinated children under the age of two and herd immunity in the unvaccinated community [18]. Children with IgG level of $>0.35 \mu \mathrm{g} / \mathrm{mL}$ are considered to have a protective antibody level towards IPDs [19]. Since these vaccines became available, a tremendous decrease in the burden of IPD caused by vaccine serotypes was observed globally. Furthermore, between 2000 and 2015 there was a 22\% global decline in clinical pneumonia cases in the general children group and of $45 \%$ in the HIV-1-infected children group [12]. The 10-valent pneumococcal vaccine (PCV10) has been introduced into the national immunization program of Ethiopia with a 3-prime dose $(3 p+0)$ schedule since 2011 [20,21].

The colonization of the nasopharynx mucous membrane by S. pneumoniae is denominated nasopharyngeal carriage. PCVs induce an IgG response which mediates neutralizing activity during S. pneumoniae infection and reduces nasopharyngeal carriage by vaccine serotypes [22]. According to Wahl and collaborators [10], $27 \%$ to $65 \%$ of children and $<10 \%$ of adults are carriers of S. pneumoniae. CD4+ T cells, through an antibody-independent mechanism, have also been shown to play a role in mediating protection against $S$. pneumoniae colonization in experimental models and exposed individuals, including children $[23,24]$. Two distinct CD4+ T cell lineages, Th1 and Th17, facilitate clearance of S. pneumoniae carriage within the nasopharynx; CD4+ T cell depletion during HIV-1 infection has been associated with defects within the Th1 T cell compartment [25], thus compromising S. pneumoniae clearance in symptomatic HIV-1-infected individuals. In this context, colonization rate in HIV-infected Malawian adults remained high following anti-retroviral treatment (ART) for 12 months [26]. Viral coinfection [27], close contact and young age have been reported to play a major role in S. pneumoniae transmission. In the era of PCVs, there is a replacement of vaccine serotypes by nonvaccine serotypes in nasopharyngeal carriage [20,21,28]. 
Healthy individuals have been reported to exhibit higher S. pneumoniae serotype-specific IgG and IgM levels compared to HIV-1-infected individuals up to one year postvaccination with PPV-23 and PCV vaccines $[29,30]$. In contrast, other studies reported a comparable level of specific IgG production in both HIV-1-infected and -uninfected individuals after PCV vaccination, although with a significant difference in the effectiveness of the produced antibodies against IPD [31,32]. Nasopharyngeal carriage of nonvaccine serotypes is still a common phenomenon in PCV-vaccinated HIV-1-infected children in Africa [33]. In this study, we assessed the maintenance of humoral responses to PCV-10 in HIV-1-infected children and age-matched controls and studied nasopharyngeal carriage in these individuals by determining the serotype of S. pneumoniae in nasopharyngeal swabs with whole-genome sequencing (WGS).

\section{Results}

\subsection{S. pneumoniae Serotype-Specific Antibody Responses}

Persistence of S. pneumoniae serotype-specific serological memory was detected in HIV-1-infected children and age-matched controls after a median time period of 4.9 years from PCV-10 vaccination; the clinical characteristics of patients and controls included in the study are presented in Table 1.

Table 1. Demographic and clinical data of the study participants.

\begin{tabular}{|c|c|c|}
\hline \multirow{2}{*}{ Characteristics } & \multicolumn{2}{|c|}{ PCV-10-Vaccinated } \\
\hline & Controls $(n=50)$ & HIV-1-Infected Children $(n=50)$ \\
\hline Median age (range) in months & $60(43-84)$ & $53.5(24-89)$ \\
\hline \multicolumn{3}{|l|}{ Gender } \\
\hline Female & $25(50 \%)$ & $27(54 \%)$ \\
\hline Male & $25(50 \%)$ & $23(46 \%)$ \\
\hline \multicolumn{3}{|l|}{ Viral load * } \\
\hline Aviremic & NA & $26(52 \%)$ \\
\hline Viremic & NA & $20(40 \%)$ \\
\hline Median viral load & NA & $42,095(266-1,882,592)$ \\
\hline \multicolumn{3}{|l|}{ ART } \\
\hline $\mathrm{ABC}+3 \mathrm{TC}+\mathrm{NVP}$ & NA & $10.3 \%$ \\
\hline $\mathrm{AZT}+3 \mathrm{TC}+\mathrm{NVP}$ & NA & $30.7 \%$ \\
\hline $\mathrm{AZT}+3 \mathrm{TC}+\mathrm{EFV}$ & NA & $10.3 \%$ \\
\hline $\mathrm{AZT}+3 \mathrm{TC}+\mathrm{LPV} / \mathrm{r}$ & NA & $23.1 \%$ \\
\hline $\mathrm{ABC}+3 \mathrm{TC}-\mathrm{LPV} / \mathrm{r}$ & NA & $25.6 \%$ \\
\hline Months on ART: median (range) & NA & $40(11-83)$ \\
\hline \multicolumn{3}{|l|}{ WHO stage * } \\
\hline Stage I & NA & 46 \\
\hline Stage III & NA & 1 \\
\hline Body mass index & $15.64(12.42-19.78)$ & $14.49(8.41-36.98)$ \\
\hline
\end{tabular}

$\mathrm{NA}=$ not applicable. ${ }^{*}=$ viral load was missing for four HIV-1-infected children and the WHO classification for three children. $\mathrm{AZT}=$ Zidovudine; $3 \mathrm{TC}=$ Lamivudine; $\mathrm{NVP}=$ Nevirapine; $\mathrm{EFV}=$ Efavirenz; $\mathrm{ABC}=$ Abacavir; $\mathrm{LPV} / \mathrm{r}=$ Lopinavir/Ritonavir.

A comparable level of serotype-specific IgG concentrations was detected in both HIV-1-infected children and age-matched controls (Figure 1).

The IgG geometric mean concentration (GMC) to all serotypes incorporated in PCV-10 was shown to be consistently higher than the conventional threshold of $0.35 \mu \mathrm{g} / \mathrm{mL}$, which is the protective threshold antibody level for IPD (Table 2), with the highest IgG GMC detected for serotype 19F $(3.59 \mu \mathrm{g} / \mathrm{mL}$ in controls and $3.36 \mu \mathrm{g} / \mathrm{mL}$ in HIV-1-infected children) and the lowest for serotype 7F $(0.63 \mu \mathrm{g} / \mathrm{mL}$ in controls) and serotype $4(0.56 \mu \mathrm{g} / \mathrm{mL}$ in HIV-1-infected children). 
Serotype 1

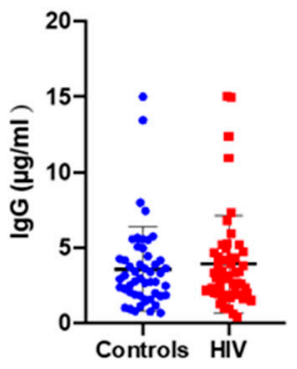

$9 \mathrm{~V}$

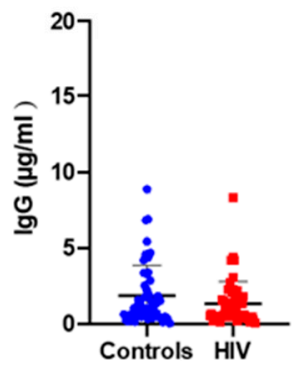

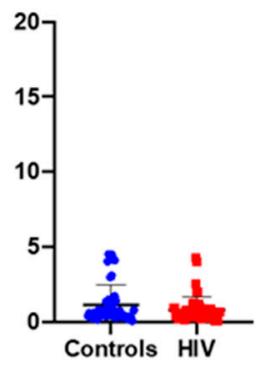

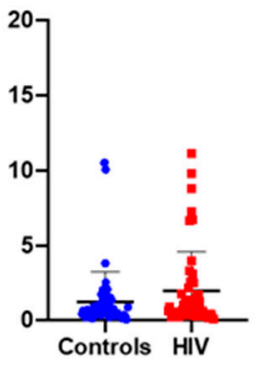

6B

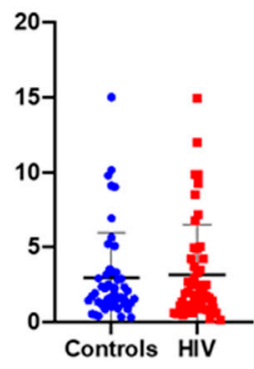

$7 F$

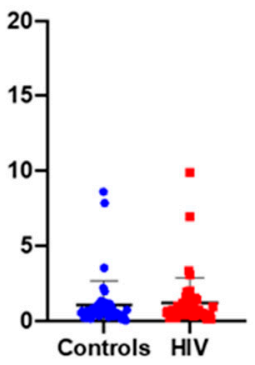

Figure 1. Median level of IgG concentration against the 10 S. pneumoniae serotypes included in PCV-10. Plasma samples from 50 control and 50 HIV-1-infected children were studied for their reactivity to PCV-10 serotype-specific IgGs.

Table 2. Geometric mean concentration (GMC) of IgG to S. pneumoniae serotypes and number of HIV-1-infected and control individuals with specific IgG concentration $\geq 0.35 \mu \mathrm{g} / \mathrm{mL}$.

\begin{tabular}{cccccccc}
\hline $\begin{array}{c}\text { Serotypes } \\
\text { PCV-10 }\end{array}$ & $\begin{array}{c}\text { GMC } \\
\text { Controls } \\
\mu \mathrm{g} / \mathbf{m L}\end{array}$ & $\begin{array}{c}\text { GMC } \\
\text { in HIV } \\
\mu \mathrm{g} / \mathbf{m L}\end{array}$ & $p$-Value & $\begin{array}{c}\text { Controls } \\
\mathbf{N}(\%)\end{array}$ & $\begin{array}{c}\text { HIV } \\
\mathbf{N}(\%)\end{array}$ & $p$-Value & Total\% \\
\hline 1 & 2.84 & 2.9 & 0.73 & $50(100)$ & $50(100)$ & $>0.99$ & 100 \\
\hline 4 & 0.71 & 0.56 & 0.19 & $41(82)$ & $34(68)$ & 0.16 & 75 \\
\hline 5 & 0.68 & 1 & 0.09 & $40(80)$ & $41(82)$ & $>0.99$ & 81 \\
\hline $6 \mathrm{~B}$ & 1.9 & 1.9 & 0.99 & $49(98)$ & $48(96)$ & $>0.99$ & 97 \\
\hline $7 \mathrm{~F}$ & 0.63 & 0.72 & 0.44 & $38(76)$ & $42(84)$ & 0.45 & 80 \\
\hline $9 \mathrm{~V}$ & 1.04 & 0.82 & 0.28 & $44(88)$ & $42(84)$ & 0.77 & 86 \\
\hline 14 & 2.78 & 2.59 & 0.92 & $47(94)$ & $48(96)$ & $>0.99$ & 95 \\
\hline $18 \mathrm{C}$ & 1.03 & 0.98 & 0.76 & $45(90)$ & $44(88)$ & $>0.99$ & 89 \\
\hline $19 \mathrm{~F}$ & 3.59 & 3.36 & 0.70 & $50(100)$ & $50(100)$ & $>0.99$ & 100 \\
\hline $23 \mathrm{~F}$ & 1.52 & 1.4 & 0.67 & $48(96)$ & $50(100)$ & 0.49 & 98 \\
\hline
\end{tabular}

${ }^{*}$ The IgG GMC was calculated using log-transformed IgG concentration for all serotypes included in PCV-10.

The percentage of individuals with antibody level $\geq 0.35 \mu \mathrm{g} / \mathrm{mL}$ lies between $75 \%$ (serotype 4 ) and 100\% (serotype 1 and 19F; Table 2), with all other serotypes in between these two values. There was no statistically significant difference between the GMCs of the two studied groups and the percentage of individuals with $\geq 0.35 \mu \mathrm{g} / \mathrm{mL}$ for the 10 serotypes. However, a lower percentage of individuals with $\geq 0.35 \mu \mathrm{g} / \mathrm{mL}$ was detected for serotype 7F (76\%) in the controls and serotype $4(68 \%)$ in the 
HIV-1-infected group compared to the other serotypes ( $>80 \%$ of protected individuals) (Table 2). A high proportion of individuals (58\% HIV-1-infected and 60\% controls) had protective antibody levels to all 10 serotypes, and $2 \%$ of children from each group showed a protective level of antibody only for 3 serotypes included in the vaccine (results not shown).

A significant positive correlation was observed between the age of the controls and serotype-specific IgG concentrations for serotype $14(p<0.01)$ and 18C $(p<0.05)$ (Figure 2). In HIV-1-infected children, on the other hand, no significant correlation was found between age and serotype-specific IgG concentration, and no differences in GMCs were observed between viremic and aviremic children (data not shown).
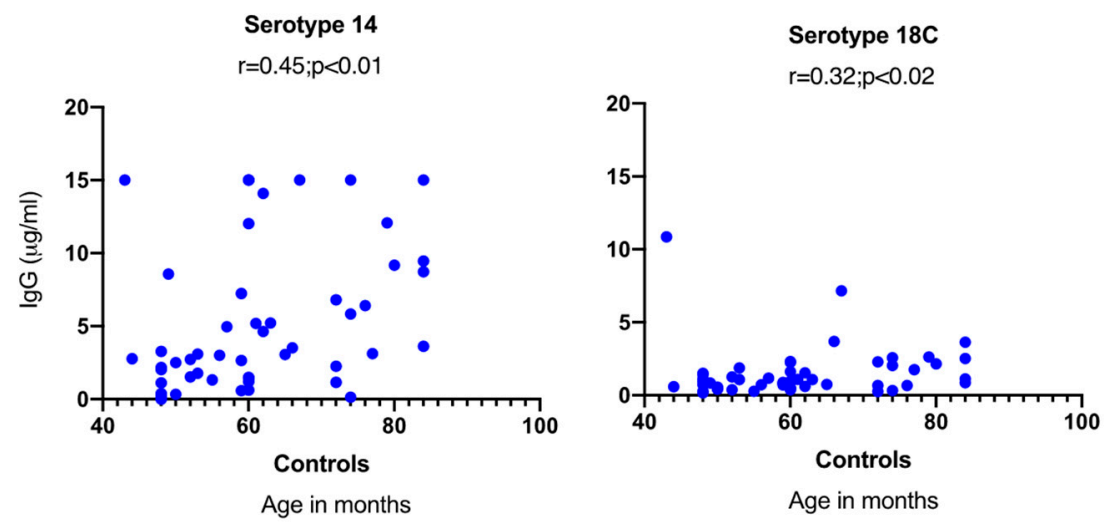

Figure 2. Correlation between age and serotype-specific IgG concentration in control children. A significant correlation was only noticed between age and specific IgG concentrations in control children for serotypes 14 and 18C.

2.2. Determination of S. pneumoniae Nasopharyngeal Carriage with Whole-Genome-Sequencing-Based Serotyping and Multi-Locus Sequence Typing (MLST)

Pneumococcal carriage was detected in 38 out of 97 (39.1\%) nasopharyngeal swabs collected from PCV-10-vaccinated children, 25 HIV-1-infected children and 13 healthy controls. A statistically significantly higher carriage rate of S. pneumoniae was detected in HIV-1-infected children (52\%) compared to age-matched healthy controls $(26.5 \%)(p=0.01)$.

Results from WGS-based pneumococcal serotyping showed that 36 S. pneumoniae isolates comprised 22 known serotypes and 2 isolates classified as nontypeable (NT). Among the isolates, non-PCV-10 serotypes represented more than $90 \%$ of the serotypes characterized (Figure 3 ). In addition to nonvaccine serotypes, two serotypes $(8.7 \%)$ are included in PCV-10 (7F and $23 \mathrm{~F})$, two $(8.7 \%$; $6 \mathrm{~A}$ and $19 \mathrm{~A})$ in PCV-13 and four (17.4\%; 11A; 12F, 15B, 20) in PPV23.

A higher percentage of vaccine serotypes were detected in HIV-1-infected children compared to age-matched healthy controls (Figure 3). PCV-10 serotypes are responsible for $8 \%$ of the carriage in HIV-1-infected children (which included a total of 25 isolates) and were not detected in the serotypes isolated $(n=13)$ from age-matched controls. PCV-13 serotypes $6 \mathrm{~A}$ and $19 \mathrm{~A}$ contributed $12 \%$ and $7.6 \%$ of pneumococcal carriage in HIV-1-infected children and controls, respectively. On the other hand, the carriage rate of vaccine serotypes incorporated in PPV23 is two times higher in controls (31\%) than in HIV-1-infected children (16\%). Despite the higher rate of PCVs serotypes carriage in HIV-1-infected children with history of PCV-10, $80 \%$ of carriage was caused by nonvaccine serotypes which are not incorporated in either PCV10 or PCV13.

Serotype 34 was the most common serotype isolated from the nasopharyngeal swabs (13.1\%). Serotypes $15 \mathrm{~A}$ and $15 \mathrm{~B}$ each contribute to $7.8 \%$ of the nasopharyngeal carriage isolates followed by $6 \mathrm{~A}$, 6C, 19A, 20 and 23A (5.2\% each), as shown in Figure 3. There was no statistically significant difference in the GMCs against S. pneumoniae serotypes between children with nasopharyngeal carriage and 
noncarriers for both groups except for serotype 14 in controls, where the noncarriers had a higher GMC than the carriers $(p=0.01)$.

\section{SEROTYPES}

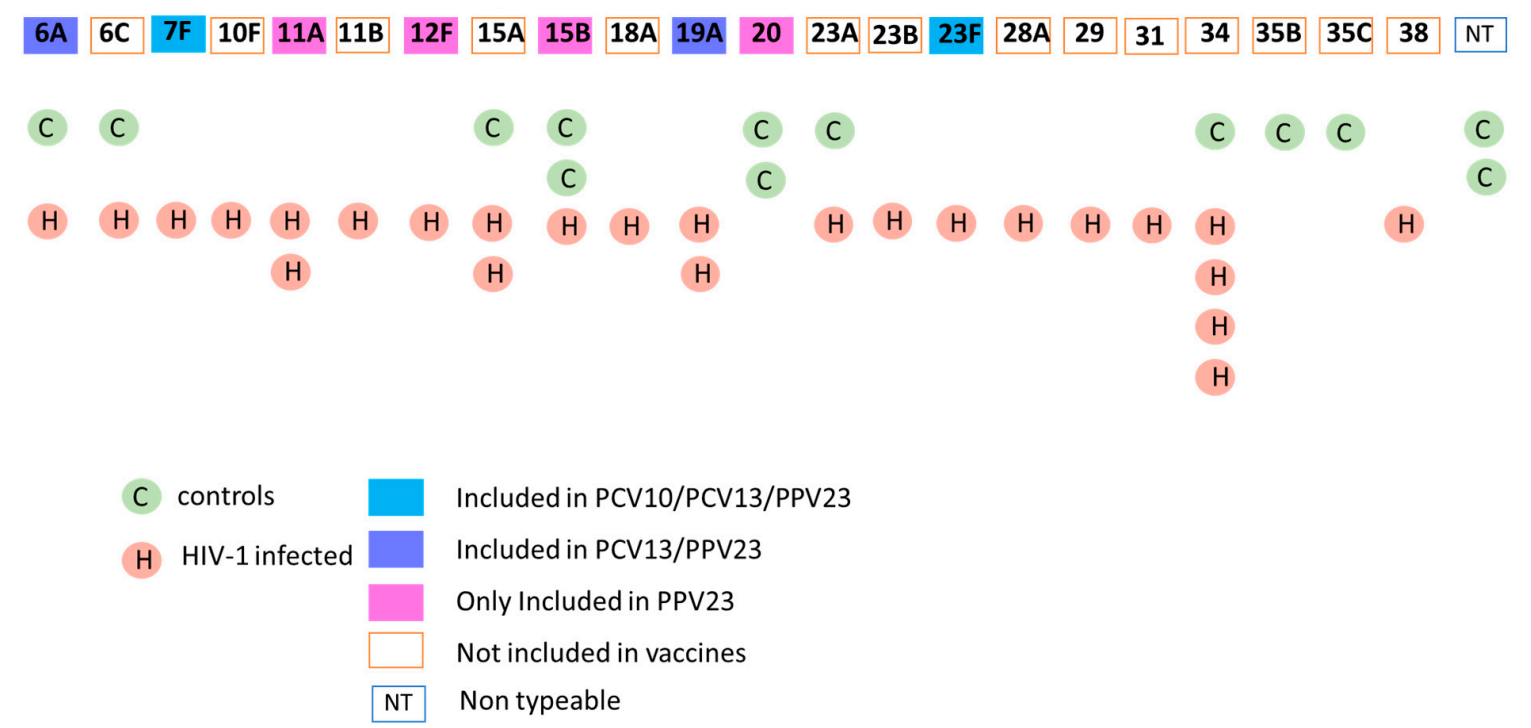

Figure 3. S. pneumoniae serotypes present in nasopharyngeal swabs of PCV-10-vaccinated HIV-1-infected and control children. The figure shows the serotype of S. pneumoniae isolates obtained from nasopharyngeal swabs of HIV-1-infected children (25 isolates) and age-matched controls (13 isolates) derived through whole-genome sequencing (WGS). The boxes filled with the different colors indicate the isolates included in the different $S$. pneumoniae vaccines; empty boxes represent the serotypes not included in the vaccines or nontypeable.

Using multi-locus sequence typing (MLST) analysis (Table 3), which, through sequencing, identifies seven alleles in the S. pneumoniae sequences, 34 S. pneumoniae sequence types (ST) were identified; among these, 12 are novel types, suggesting that $S$. pneumoniae strains from Ethiopia may be underrepresented in the MLST database. ST11162 is the most frequent sequence type, followed by ST344 and ST156. In addition, various sequence types were also comprised in the same serotype: serotype 34 (ST11546, ST5934 and three novel STs), serotype 15A (ST991, ST2318 and one novel ST), serotype 23A (ST4168 and one novel ST) and serotype 20 (ST13704 and one novel ST). A graphical representation of the MLST findings is presented in Figure 4 showing a network tree where the phylogenetic relationship of the alleles characterized from the different S. pneumoniae isolates is shown. As shown in Figure 4, some novel STs are single- or double-loci variants, but for other STs, several loci variations were identified.

Table 3. Genetic characteristics of S. pneumoniae isolates from nasopharyngeal carriage.

\begin{tabular}{|c|c|c|c|c|c|c|c|c|c|c|}
\hline \multirow[t]{2}{*}{ Sample ID } & \multirow[t]{2}{*}{ Age (Months) } & \multicolumn{7}{|c|}{ Allele No.\# } & \multirow[t]{2}{*}{$\begin{array}{c}\text { MLST } \\
\text { Sequence Type\# }\end{array}$} & \multirow[t]{2}{*}{ Serotypea } \\
\hline & & aroE & $g d h$ & $g k i$ & recP & spi & $x p t$ & $d d l$ & & \\
\hline $\mathrm{C} 12$ & 50 & 7 & 13 & 8 & 5 & 9 & 6 & 8 & 848 & $6 \mathrm{C}$ \\
\hline $\mathrm{C} 15$ & 49 & 6 & 28 & 4 & 5 & 17 & 20 & 148 & 11162 & $15 \mathrm{~B}$ \\
\hline $\mathrm{C} 16$ & 72 & 6 & 28 & 4 & 5 & 17 & 20 & 148 & 11162 & 15B \\
\hline C19 & 60 & 8 & 5 & 4 & 1 & 6 & 1 & 6 & 2318 & $15 \mathrm{~A}$ \\
\hline $\mathrm{C} 21$ & 84 & 7 & 13 & 8 & 6 & 15 & 2 & 8 & 4168 & $23 \mathrm{~A}$ \\
\hline $\mathrm{C} 26$ & 63 & 1 & 16 & 4 & 17 & 7 & 1 & 14 & 13704 & 20 \\
\hline
\end{tabular}


Table 3. Cont.

\begin{tabular}{|c|c|c|c|c|c|c|c|c|c|c|}
\hline \multirow[t]{2}{*}{ Sample ID } & \multirow[t]{2}{*}{ Age (Months) } & \multicolumn{7}{|c|}{ Allele No.\# } & \multirow{2}{*}{$\begin{array}{c}\text { MLST } \\
\text { Sequence Type\# }\end{array}$} & \multirow[t]{2}{*}{ Serotypea } \\
\hline & & aroE & $g d h$ & $g k i$ & recP $P$ & spi & $x p t$ & $d d l$ & & \\
\hline $\mathrm{C} 29$ & 53 & 8 & 37 & 9 & 29 & 2 & 12 & 53 & 344 & NT \\
\hline $\mathrm{C} 30$ & 52 & 8 & 37 & 9 & 29 & 2 & 12 & 53 & 344 & NT \\
\hline $\mathrm{C} 33$ & 52 & 1 & 2 & 29 & 4 & 43 & 277 & 255 & Novel 1 & 20 \\
\hline C48 & 48 & 6 & 57 & 83 & 28 & 7 & 1 & 15 & 2906 & $6 \mathrm{~A}$ \\
\hline C49 & 60 & 162 & 13 & 4 & 10 & 17 & 115 & 28 & 5934 & 34 \\
\hline C54 & 48 & 8 & 5 & 36 & 3 & 6 & 1 & 17 & Novel 2 & $35 \mathrm{C}$ \\
\hline C67 & 74 & 7 & 13 & 4 & 5 & 7 & 88 & 9 & 373 & $35 \mathrm{~B}$ \\
\hline HIV02 & 53 & 8 & 5 & 36 & 3 & 15 & 1 & 6 & Novel 3 & 29 \\
\hline HIV04 & 82 & 12 & 5 & 89 & 8 & 6 & 112 & 14 & 989 & $12 \mathrm{~F}$ \\
\hline HIV05 & 70 & 2 & 42 & 2 & 1 & 6 & 115 & 20 & 6465 & $10 \mathrm{~F}$ \\
\hline HIV08 & 48 & 2 & 42 & 9 & 1 & 6 & 19 & 20 & 6455 & $6 \mathrm{~A}$ \\
\hline HIV12 & 75 & 162 & 13 & 196 & 10 & 17 & 115 & 28 & Novel 4 & 34 \\
\hline HIV18 & 40 & 10 & 20 & 14 & 1 & 6 & 1 & 29 & 218 & $7 \mathrm{~F}$ \\
\hline HIV20 & 61 & 2 & 16 & 8 & 6 & 25 & 6 & 28 & Novel 5 & $23 \mathrm{~A}$ \\
\hline HIV21 & 76 & 25 & 31 & 4 & 5 & 32 & 28 & 44 & 5063 & $18 \mathrm{~A}$ \\
\hline HIV22 & 95 & 1 & 32 & 227 & 1 & 15 & 26 & 11 & 5823 & $28 \mathrm{~A}$ \\
\hline HIV23 & 76 & 7 & 13 & 8 & 5 & 3 & 6 & 8 & Novel 6 & 23B1 \\
\hline HIV26 & 43 & 2 & 12 & 9 & 1 & 6 & 20 & 5 & 6476 & $11 \mathrm{~B}$ \\
\hline HIV27 & 44 & 2 & 13 & 8 & 6 & 25 & 6 & 14 & 2345 & $19 \mathrm{~A}$ \\
\hline HIV30 & 40 & 7 & 11 & 10 & 1 & 6 & 8 & 1 & 156 & $11 \mathrm{~A}$ \\
\hline HIV31 & 89 & 162 & 42 & 4 & 10 & 17 & 115 & 28 & Novel 7 & 34 \\
\hline HIV32 & 75 & 1 & 2 & 29 & 1 & 43 & 7 & 8 & Novel 8 & 31 \\
\hline HIV33 & 26 & 12 & 19 & 36 & 17 & 6 & 20 & 14 & 2013 & $19 \mathrm{~A}$ \\
\hline HIV34 & 31 & 6 & 28 & 4 & 5 & 17 & 20 & 148 & 11162 & $15 \mathrm{~B}$ \\
\hline HIV35 & 50 & 7 & 11 & 10 & 1 & 6 & 8 & 1 & 156 & $11 \mathrm{~A}$ \\
\hline HIV38 & 84 & 7 & 13 & 8 & 5 & 6 & 6 & 124 & 988 & $23 \mathrm{~F}$ \\
\hline HIV40 & 24 & 10 & 34 & 4 & 10 & 495 & 405 & 75 & Novel 9 & 34 \\
\hline HIV41 & 81 & 10 & 13 & 4 & 10 & 495 & 405 & 8 & 11546 & 34 \\
\hline HIV42 & 49 & 54 & 5 & 4 & 1 & 6 & 1 & 111 & 991 & $15 \mathrm{~A}$ \\
\hline HIV55 & 52 & 58 & 5 & 4 & 1 & 218 & 79 & 5 & Novel 10 & $6 \mathrm{C}$ \\
\hline HIV76 & 34 & 7 & 5 & 8 & 5 & 9 & 6 & 8 & Novel 11 & $15 \mathrm{~A}$ \\
\hline HIV77 & 83 & 2 & 555 & 673 & 1 & 6 & 83 & 31 & Novel 12 & 38 \\
\hline
\end{tabular}

\# = The microbial sequence analysis and loci-based typing pipeline MicroSALT v. 2.8.9 (https://github.com/ClinicalGenomics/microSALT) was utilized to analyze the sequence data. $a=$ The serotypes of the strains were predicted using SeroBA v. 1.0.1 [34]. 


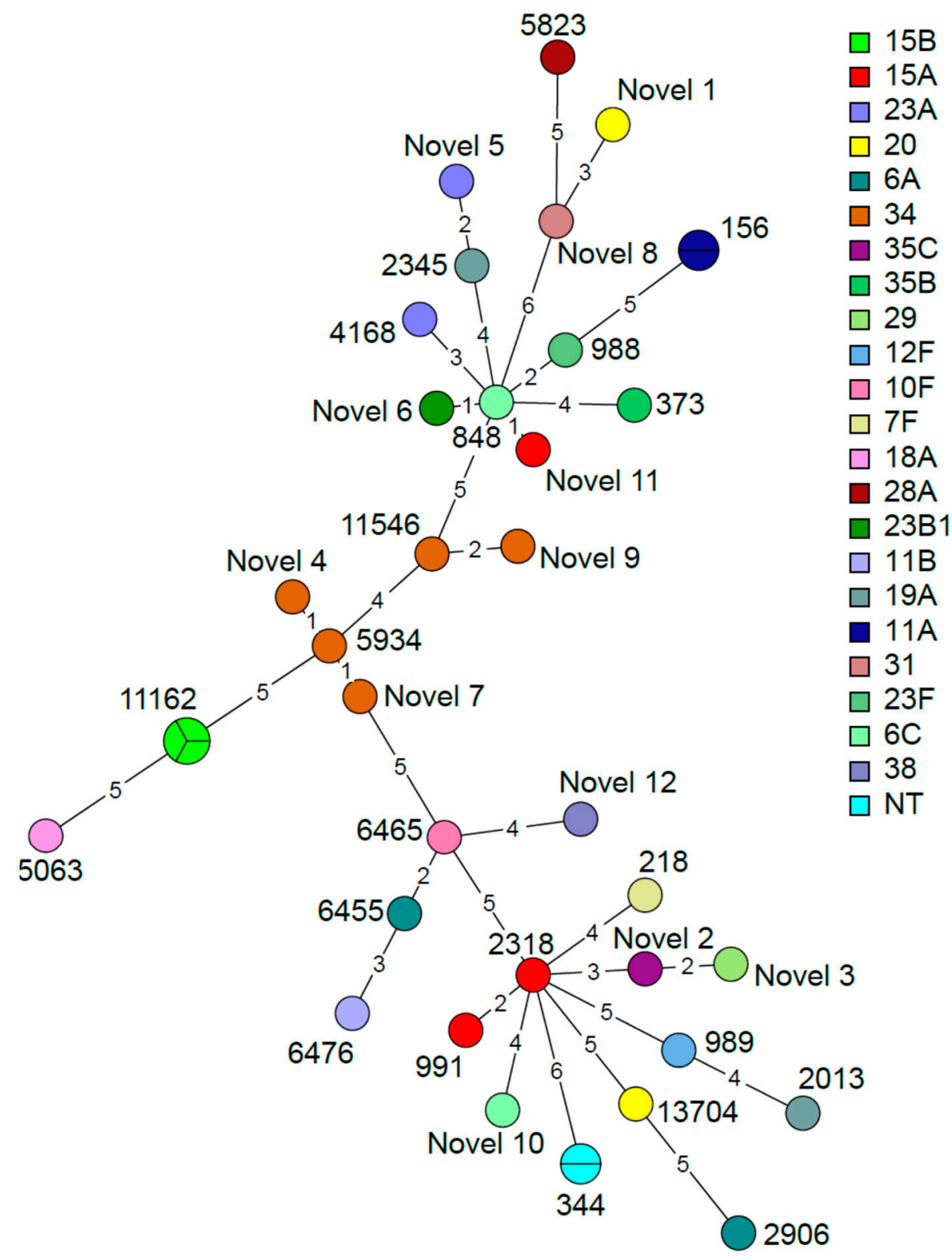

Figure 4. Minimum spanning tree based on the multi-locus sequence typing (MLST) results of the $38 \mathrm{~S}$. pneumoniae isolates grouped by sequence type. The nodes are colored according to serotype. The size and partition of the nodes indicate how many samples are included in each node. The branch length indicates the number of alleles that differ between the sequence types.

\subsection{S. pneumoniae Serotype-Specific Antibody Responses in Relation to Nasopharyngeal Carriage}

It has been previously suggested that protection from S. pneumoniae carriage should be evaluated considering different IgG thresholds for the different serotypes included in PCV-10 or PCV-13 [35]. We took into consideration these different thresholds and calculated the frequency of individuals who showed levels of protective antibody responses against carriage with the different serotypes. The results are presented in Table 4. The largest frequency of individuals showing protective levels was detected for serotypes $1(94 \%)$ and $6 \mathrm{~B}(93 \%)$ and the lowest for serotypes $4(26 \%)$ and $7 \mathrm{~F}(13 \%)$, and these values were comparable in both groups of healthy controls and HIV-1-infected children. These results should be taken into consideration when evaluating the complex picture of immunological interactions ensuring protection against S. pneumoniae carriage. It is interesting and puzzling that the two HIV-1-infected children displaying nasopharyngeal carriage for PCV-10 serotypes 7F and 23F had 
protective levels against the two serotypes substantially above ( 9.89 and $2.1 \mu \mathrm{g} / \mathrm{mL}$, respectively) the suggested threshold value suggested for $7 \mathrm{~F}$ and $23 \mathrm{~F}$ serotypes in plasma.

Table 4. Percentage of HIV-1-infected and control children with S. pneumoniae serotype-specific IgG concentration considered protective for $S$. pneumoniae carriage.

\begin{tabular}{|c|c|c|c|c|c|}
\hline $\begin{array}{l}\text { Serotypes } \\
\text { in PCV-10 }\end{array}$ & $\begin{array}{l}\text { Antibody Threshold * } \\
\qquad(\mu \mathrm{g} / \mathrm{mL})\end{array}$ & $\begin{array}{c}\text { Positive Controls } \\
\text { N (\%) }\end{array}$ & $\begin{array}{l}\text { Positive HIV-1 } \\
\text { Infected } \\
\text { N (\%) }\end{array}$ & $p$-Value & $\begin{array}{l}\text { \% of Total } \\
\text { Children }\end{array}$ \\
\hline 1 & 0.81 & $46(92 \%)$ & 48 (96\%) & 0.68 & $94 \%$ \\
\hline 4 & 1.16 & $15(30 \%)$ & $11(22 \%)$ & 0.49 & $26 \%$ \\
\hline 5 & 0.73 & $23(46 \%)$ & $30(60 \%)$ & 0.22 & $53 \%$ \\
\hline $6 \mathrm{~B}$ & 0.5 & $46(92 \%)$ & 47 (94\%) & $>0.99$ & $93 \%$ \\
\hline $7 \mathrm{~F}$ & 1.6 & $5(10 \%)$ & $8(16 \%)$ & 0.55 & $13 \%$ \\
\hline $9 \mathrm{~V}$ & 1.31 & $22(44 \%)$ & $20(40 \%)$ & 0.84 & $42 \%$ \\
\hline 14 & 2.48 & $32(64 \%)$ & $30(60 \%)$ & 0.84 & $62 \%$ \\
\hline $18 \mathrm{C}$ & 1.32 & $18(36 \%)$ & $18(36 \%)$ & $>0.99$ & $36 \%$ \\
\hline $19 \mathrm{~F}$ & 2.54 & $35(70 \%)$ & $30(60 \%)$ & 0.40 & $65 \%$ \\
\hline $23 \mathrm{~F}$ & 0.63 & $42(84 \%)$ & $41(82 \%)$ & $>0.99$ & $83 \%$ \\
\hline
\end{tabular}

\section{Discussion}

This study is the first study to report, in Ethiopia, the maintenance of S. pneumoniae serotype-specific antibody responses in ART-treated HIV-1-infected children and age-matched controls previously vaccinated with PCV-10. The children's median age was 4.9 years, and they had all received a full dose of PCV-10 at 6, 10 and 14 weeks of age. In the study, similar percentages of HIV-1-infected children and age-matched controls were found to carry antibody concentrations considered to be protective against IPD $(\geq 0.35 \mu \mathrm{g} / \mathrm{mL})$ for all serotypes included in PCV-10. A study conducted by Madhi and collaborators [36] reported a similar result among HIV-1-infected and noninfected children who had received PCV10 (three doses plus one booster) with samples collected 14 months after the booster. Furthermore, the persistence of serotype-specific IgG responses in non-HIV-1-infected children reported by other studies after 3, 4 and 5 years of completed PCV-10 vaccination is comparable with our results [37-39]. These findings confirm the ability of PCV-10 to induce a long-lasting serotype-specific IgG response. The maintenance of high protective levels of $S$. pneumoniae antibodies in plasma after two to six years of vaccination may, on the other hand, also reflect natural exposure to S. pneumoniae serotypes included in PCV10, which may reinvigorate immunological memory elicited during vaccination.

It has previously been reported that, in the current era of PCVs, there is a replacement of vaccine by nonvaccine $S$. pneumoniae serotypes, with the latter isolated from nasopharyngeal carriage and IPD patients, particularly in individuals with underlying conditions including HIV-1 infection [20,21,28,40]. In this study, nasopharyngeal carriage was detected in $39.1 \%$ of children who had received the full dose of PCV-10, with over $90 \%$ of the carriage caused by nonvaccine serotypes not included in PCV-10. The carriage rate in the vaccinated children included in the present study is higher than that previously reported in Ethiopia (21.5\%) [20].

In contrast to the comparable amount of specific plasma IgG levels to the serotypes included in PCV-10, we detected that the carriage rate in HIV-1-infected children (52\%) was twice the carriage rate in age-matched controls (26.5\%); carriage of vaccine serotypes $7 \mathrm{~F}$ and $23 \mathrm{~F}$ was only detected in the HIV-1-infected group. This result indicates the need for immunological studies assessing the mechanisms of immune responses against pneumococcal nasopharyngeal carriage in PCV-10-vaccinated 
individuals, particularly in HIV-1-infected children, in areas with a high burden of pneumococcal diseases. Apart from 7F and 23F, nasopharyngeal carriage by other serotypes included in PCV-10, serotypes 1, 4, 14 and 19F, was previously reported in Ethiopia [20,21]. PCV13 serotypes 6A and 19A each contributed $5.2 \%$ of pneumococcal carriage in our study; this result is significantly lower than what previously shown by Negash et al. [20] for 19A (27\%) but comparable to what was shown for 6A $(4.9 \%)$ in children with CAP after 5 years of PCV-10 introduction. All S. pneumoniae serotypes reported in this study, except 28A, were previously reported in nasopharyngeal carriers in Ethiopia [20,21]. The MLST analyses, which characterize microorganisms by their allelic profiles, suggested that 12 of the 38 S. pneumoniae isolates in our study carry novel combinations of alleles; a large scale study should be performed in Ethiopia to further characterize the genomic profile of S. pneumoniae and the novelty degree of the alleles identified by us. Most carriage serotypes isolated and characterized in our study have previously been associated with complications of $S$. pneumoniae infection, from otitis media to IPD cases, including pneumococcal meningitis, in different parts of the world [40-43]. Therefore, our findings on the carriage in HIV-1-infected children are worrisome as these individuals, despite ART treatment and PCV-10 vaccination, remain at high risk for S. pneumoniae-related complications.

The immunological mechanisms responsible for protection against $S$. pneumoniae carriage remain elusive, and arguments have previously been presented for innate and adaptive immune responses playing a role in this context. MZ B cells, which are found in the spleen MZ [44] and to some extent also in blood, play an important role in T-cell-independent humoral immunity to encapsulated bacteria rich in polysaccharides antigens, including S. pneumoniae [45]. MZ B cells are fully developed in humans around two years of age [46]. A decline in frequency of mature MZ B cells has been reported in the blood of HIV-1-infected children, probably due to impaired migratory capacity of these cells [47]. HIV-1 infection leads to the dysregulation of several B cell subpopulations, including memory B cells [48,49], which, together with MZ B cells, are associated with maintenance of serological memory to PCV vaccination. Inflammation and impaired control of human innate immune responses have recently emerged as important pathogenic players in establishment of $S$. pneumoniae infection and associated clinical conditions [50]; respiratory viruses may play a negative role in carriage establishment by leading to increased inflammation.

It is still unclear whether protection from nasopharyngeal colonization by vaccine serotypes is due to IgG and/or IgA produced locally or by the leakage of circulating IgG into the mucosa. Despite the observation that PCVs induce comparable amounts of serotype-specific S. pneumoniae antibodies in HIV-1-infected and noninfected individuals, the functional capacity of these antibodies to neutralize $S$. pneumoniae, as measured by opsonophagocytic assay, was lower in the HIV-1-infected group [51,52]. According to an analysis conducted by Voysey M. et al. [35], the antibody concentration required for protection against pneumococcal carriage varies for each serotype, and a higher antibody concentration is needed for carriage protection in developing countries. In our study, there was no significant difference in the S. pneumoniae serotype-specific antibody concentration between HIV-1-infected and control children using the reference reported by Voysey M. et al. [35]. Voysey M. [35] also suggested that pneumococcal antibody thresholds of protection may be different in low- and high-income countries [35]; further studies conducted in African countries may, however, be needed to create reference values for protection against pneumococcal carriage in this continent. The balance between Th17 and Treg cells in nasopharynx-associated lymphoid tissue has been reported to play a role for clearance of S. pneumoniae in this compartment; Th17 cell frequencies increase with age [53]. The lack of knowledge on the CD4+ T cell counts is a limitation of the present study. Longitudinal studies in HIV-1-infected and noninfected children, regularly assessing memory and MZ B cells before and after PCV-10 vaccination in parallel with determination of T cells and antibody responses to S. pneumoniae serotypes and carriage, may lead to significant information on the relation between cellular and serological components relevant to protection from S. pneumoniae infection and carriage. 


\section{Material and Methods}

\subsection{Study Population}

A cross-sectional study was conducted between May 2018 and March 2019, which included 50 ART-treated HIV-1-infected children (median age in months and range 53.5 (24-89)) and 50 age-matched controls (age and range 60 (43-84)) who had received 3 primary doses of 10-valent pneumococcal vaccine (PCV-10) according to the Ethiopian childhood immunization program. Vaccination history was confirmed using a vaccination history record. All HIV-1-infected children were recruited from ALERT Hospital, Zewditu Memorial Hospital and Yekatit 12 Hospital ART clinics and control subjects from Woreda 03 Health Center, Addis Ababa.

HIV-1 RNA copies were quantified in plasma of HIV-1-infected children using an automated m2000sp Abbott Real-Time HIV-1 assay system following the manufacturer's protocol (Abbott Laboratories, Abbott Park, IL, USA) (Table 1). The lower detection limit of this assay was 40 copies $/ \mathrm{mL}$. Viremia was detected in $40 \%$ of HIV-1-infected children with a median viral load of 42,095 copies/mL (range 266-1,882,592). There was no correlation between the viremic status, age and length of treatment.

Blood samples were collected from all study participants; plasma was isolated and stored at $-80^{\circ} \mathrm{C}$. Nasopharyngeal swab specimens $(n=97)$ were obtained using a flexible calcium alginate-tipped swab which was stored in skim milk-tryptone-glucose glycerin medium (STGG) at $-80{ }^{\circ} \mathrm{C}$. Samples were transported frozen to Karolinska Institutet for further analyses.

\subsection{Measurement of S. pneumoniae Serotype Specific IgG in Plasma}

The plasma concentration of IgG specific for the 10 individual S. pneumoniae serotypes included in PCV-10 was measured by ELISA using purified pneumococcal polysaccharide antigens donated from SSI Diagnostica (Hillerød, Denmark) and 007SP as a standard reference serum (gift from Dr. Mustafa Akkoyunlu, FDA, USA). The WHO guideline for pneumococcal ELISA was followed with few modifications [54]. Briefly, ELISA plates were coated using $5 \mu \mathrm{g} / \mathrm{mL}$ of purified pneumococcal polysaccharide. The coated plates were incubated for $5 \mathrm{~h}$ at $37^{\circ} \mathrm{C}$ and stored overnight at $+4{ }^{\circ} \mathrm{C}$. Thereafter, they were washed using $0.05 \%$ tween in PBS and blocked using $1 \%$ BSA. To avoid nonspecific binding, standard reference serum and serum samples were adsorbed using an adsorption solution which contains $10 \mu \mathrm{g} / \mathrm{mL}$ of pneumococcal cell wall polysaccharide and S. pneumoniae serotype $22 \mathrm{~F}$ for $1 \mathrm{~h}$ at $37^{\circ} \mathrm{C}$. Following adsorption, $100 \mu \mathrm{L}$ of standard and serum samples were added to the plates in duplicate. After $2 \mathrm{~h}$ of incubation, $100 \mu \mathrm{L}$ of anti-human IgG secondary antibody conjugated with alkaline phosphatase were added, followed by substrate (p-nitrophenyl phosphate) and $3 \mathrm{M} \mathrm{NaOH}$ stopping solution after $1 \mathrm{~h}$ incubation at room temperature. All samples and standards were tested in duplicate. Interpolation of concentration for the samples was done in GraphPad Prism 8. Children with IgG level of $\geq 0.35 \mu \mathrm{g} / \mathrm{mL}$ are considered to have IPD-protective antibody levels [19].

\subsection{Identification of S. pneumoniae from Nasopharynx Swabs and DNA Isolation}

Culture-based identification of S. pneumoniae from nasopharyngeal swabs was conducted using the 2016 CDC guidelines [55]. Each swab was plated into trypticase soy agar (TSA) plates supplemented with $5 \%$ sheep blood containing $5 \mu \mathrm{g} / \mathrm{mL}$ gentamicin. Identification of $S$. pneumoniae was performed based on colony morphology and Optochin susceptibility. Pure $\alpha$-hemolytic optochin susceptible

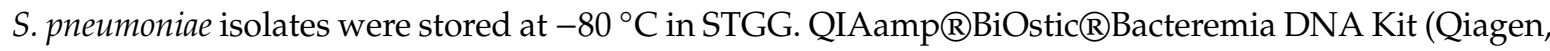
Hilden, Germany) was used for DNA isolation.

\subsection{Whole Genome Sequence-Based S. pneumoniae Serotyping}

Whole-genome sequencing was conducted at Scilife Laboratory (Stockholm, Sweden). Genomic DNA was quantified using Quant-iT ${ }^{\mathrm{TM}}$ dsDNA High-Sensitivity Assay Kit and FLUOstar Omega plate reader. Samples were normalized to $2 \mathrm{ng} / \mu \mathrm{L} ; 1 \mu \mathrm{L}$ of normalized genomic DNA was used in the tagmentation reaction using Nextera chemistry (Illumina, San Diego, CA, USA) to yield fragments 
of approximately $410 \mathrm{bp}$. Amplification of tagmented library was carried out using 11 cycles of PCR with Unique Dual Index (UDI) (IDT Technologies, Coralville, IA, USA). The resulting PCR products were purified using Sera-Mag beads (GE Healthcare Life Sciences, Uppsala Sweden). The obtained library was quantified using Quant-iT ${ }^{\mathrm{TM}}$ dsDNA High-Sensitivity Assay Kit and FLUOstar Omega plate reader. Library was pair-end (2x151 bp) sequenced to minimum $3 \mathrm{M}$ read pairs on NovaSeq 6000 (Illumina, San Diego, CA, USA). Base-calling and demultiplexing was done using bcl2fastq v2.20.0.422, allowing one mismatch in the index sequence.

The microbial sequence analysis and loci-based typing pipeline MicroSALT v. 2.8 .9 (https:// github.com/Clinical-Genomics/microSALT) was utilized to analyze the sequence data. MicroSALT is an open-source pipeline that is based on publicly available software. The software that are included in the pipeline are BLAST v. 2.9.0, BWA v. 0.7.17 [56], Picard tools v 2.20.3 (https://github.com/broadinstitute/ picard), QUAST v. 5.0.2 [57], SAMtools v 1.9 [58], SPAdes v. 3.13 .1 [59] and Trimmomatic v. 0.39 [60]. MicroSALT utilizes the databases PubMLST and ResFinder. BLAST was utilized to search in PubMLST to assign sequence type loci to the assembled sequences.

The serotypes of the strains were predicted using SeroBA v. 1.0.1 [34]. The k-mer counts database was built through SeroBA using the recommended setting for the kmer size (71 bp). Default settings were utilized for the analysis except that, in order to include all serotypes in the ARIBA-compatible database, the maximum allowed length in nucleotides of non-coding sequences was set to 25,000 bp.

The results of the MLST and serotype analyses are visualized in a minimum spanning tree using the BioNumerics software (Version 7.6, Applied Maths NV, Sint-Martens-Latem, Belgium).

\subsection{Statistical Analysis}

Demographic and clinical data were analyzed using Graph pad prism 8 (La Jolla, CA, USA). The normal distribution of ELISA data was assessed using Kolmogorov-Smirnov test. Unpaired T-test was used to assess the difference between groups. Fisher exact test was used to compare frequency between groups. Spearman correlation was applied to determine the relation of variables. A $p$-value $<0.05$ was considered statistically significant.

\subsection{Ethical Statement}

Ethical clearance to conduct the current study was obtained from the ethical clearance committee of ALERT/AHRI ethics review committee (protocol number P0/06/17) and Ethiopian national ethical review committee (NERC; reference n. 3.10/71/2018). Informed written consent was collected from parents or legal guardians of children in the study. The study was conducted in accordance with the Declaration of Helsinki. The ethical committee at Karolinska Institutet approved the laboratory studies of the collected specimens (approval n 2016/485-32).

Author Contributions: Conceptualization, M.L.; F.C.; A.A. B.P., R.H.; methodology, M.L., Y.B., S.P., M.H.; validation, M.L., M.H.; investigation, M.L., Y.B., S.P., M.H.; data curation, M.L., Y.B., S.P., M.H.; writing-original draft preparation, M.L., F.C.; visualization, M.L., M.H.; supervision, F.C., B.P., A.A., R.H.; project administration, F.C.; funding acquisition, A.A., F.C. All authors have read and agreed to the published version of the manuscript.

Funding: The study was supported through grants from the Swedish Medical Research Council (grant number 2016-01165) and the Biomedical Science Postgraduate training Program (BSPP) funded by a grant to AHRI (Ethiopia) from the Swedish International Development Agency (SIDA ) for research cooperation with Swedish Universities (grant number 51080091).

Acknowledgments: We acknowledge the help of Abel Negash for advice in collection of nasopharyngeal swabs.

Conflicts of Interest: The authors declare no conflict of interest.

\section{References}

1. Hackel, M.; Lascols, C.; Bouchillon, S.; Hilton, B.; Morgenstern, D.; Purdy, J. Serotype prevalence and antibiotic resistance in Streptococcus pneumoniae clinical isolates among global populations. Vaccine 2013, 31, 4881-4887. [CrossRef] 
2. Donkor, E.S. Understanding the pneumococcus: Transmission and evolution. Front. Cell. Infect. Microbiol. 2013, 3, 7. [CrossRef] [PubMed]

3. Henriques-Normark, B.; Tuomanen, E.I. The Pneumococcus: Epidemiology, microbiology, and pathogenesis. Cold Spring Harb. Perspect. Med. 2013, 3, a010215. [CrossRef] [PubMed]

4. Weiser, J.N. The pneumococcus: Why a commensal misbehaves. J. Mol. Med. 2010, 88, 97-102. [CrossRef] [PubMed]

5. Sonego, M.; Pellegrin, M.C.; Becker, G.; Lazzerini, M. Risk factors for mortality from acute lower respiratory infections (ALRI) in children under five years of age in low and middle-income countries: A systematic review and meta-analysis of observational studies. PLoS ONE 2015, 10, e0116380. [CrossRef]

6. Torres, A.; Blasi, F.; Dartois, N.; Akova, M. Which individuals are at increased risk of pneumococcal disease and why? Impact of COPD, asthma, smoking, diabetes, and/or chronic heart disease on community-acquired pneumonia and invasive pneumococcal disease. Thorax 2015, 70, 984-989. [CrossRef]

7. Curcio, D.; Cané, A.; Isturiz, R. Redefining risk categories for pneumococcal disease in adults: Critical analysis of the evidence. Int. J. Infect.Dis. 2015, 37, 30-35. [CrossRef]

8. Feldman, C.; Anderson, R.; Rossouw, T. HIV-related pneumococcal disease prevention in adults. Expert Rev. Respir. Med. 2017, 11, 181-199. [CrossRef]

9. Weiser, J.N.; Ferreira, D.M.; Paton, J.C. Streptococcus pneumoniae: Transmission, colonization and invasion. Nat. Rev. Microbiol. 2018, 16, 355-367. [CrossRef]

10. Wahl, B.; O’Brien, K.L.; Greenbaum, A.; Majumder, A.; Liu, L.; Chu, Y.; Lukšić, I.; Nair, H.; McAllister, A.D.; Campbell, H.; et al. Burden of Streptococcus pneumoniae and Haemophilus influenzae type b disease in children in the era of conjugate vaccines: Global, regional, and national estimates for 2000-2015. Lancet Glob. Health 2018, 6, e744-e757. [CrossRef]

11. World Health Organization (WHO). Pneumococcal Conjugate Vaccines in Infants and Children under 5 Years of Age: WHO Position Paper Weekly Epidemiological Record; WHO: Geneva, Switzerland, 2019; Volume 94, pp. 85-104.

12. McAllister, D.A.; Liu, L.; Shi, T.; Chu, Y.; Reed, C.; Burrows, J.; Adeloye, D.; Rudan, I.; Black, R.E.; Campbell, H.; et al. Global, Regional, and national estimates of pneumonia morbidity and mortality in children younger than 5 years between 2000 and 2015: A systematic analysis. Lancet Glob. Health 2019, 7, e47-e57. [CrossRef]

13. Bliss, S.J.; O’Brien, K.L.; Janoff, E.N.; Cotton, M.F.; Musoke, P.; Coovadia, H.; Levine, O.S. The evidence for using conjugate vaccines to protect HIV-infected children against pneumococcal disease. Lancet Infect. Dis. 2008, 8, 67-80. [CrossRef]

14. Daniels, C.C.; Rogers, P.D.; Shelton, C.M. A review of pneumococcal vaccines: Current polysaccharide vaccine recommendations and future protein antigens. J. Pediatr. Pharmacol. Ther. 2016, 21, 27-35. [CrossRef] [PubMed]

15. Westerink, M.A.; Schroeder, H.W.; Nahm, M.H. Immune Responses to pneumococcal vaccines in children and adults: Rationale for age-specific vaccination. Aging Dis. 2012, 3, 51-67.

16. Goldblatt, D.; Borrow, R.; Miller, E. Natural and vaccine-induced immunity and immunologic memory to Neisseria meningitidis serogroup C in young adults. J. Infect. Dis. 2002, 185, 397-400. [CrossRef]

17. Weller, S.; Braun, M.C.; Tan, B.K.; Rosenwald, A.; Cordier, C.; Conley, M.E.; Plebani, A.; Kumararatne, D.S.; Bonnet, D.; Tournilhac, O.; et al. Human blood IgM "memory" B cells are circulating splenic marginal zone B cells harboring a prediversified immunoglobulin repertoire. Blood 2004, 104, 3647-3654. [CrossRef]

18. Rodgers, G.L.; Klugman, K.P. Surveillance of the impact of pneumococcal conjugate vaccines in developing countries. Hum. Vaccin Immunother. 2016, 12, 417-420. [CrossRef]

19. World Health Organization (WHO). Correlates of Vaccine-Induced Protection: Methods and Implications; WHO/IVB/13.01; WHO: Geneva, Switzerland, 2013; pp. 1-55.

20. Negash, A.A.; Asrat, D.; Abebe, W.; Hailemariam, T.; Gebre, M.; Verhaegen, J.; Aseffa, A.; Vaneechoutte, M. Pneumococcal carriage, serotype distribution, and risk factors in children with community-acquired pneumonia, 5 years after introduction of the 10-valent pneumococcal conjugate vaccine in ethiopia. Open Forum Infect. Dis. 2019, 6, ofz259. [CrossRef]

21. Sime, W.T.; Aseffa, A.; Woldeamanuel, Y.; Brovall, S.; Morfeldt, E.; Henriques-Normark, B. Serotype and molecular diversity of nasopharyngeal Streptococcus pneumoniae isolates from children before and after 
vaccination with the ten-valent pneumococcal conjugate vaccine (PCV10) in Ethiopia. BMC Infect. Dis. 2019, 19, 409. [CrossRef]

22. Mitsi, E.; Roche, A.M.; Reine, J.; Zangari, T.; Owugha, J.T.; Pennington, S.H.; Gritzfeld, J.F.; Wright, A.D.; Collins, A.M.; van Selm, S.; et al. Agglutination by anti-capsular polysaccharide antibody is associated with protection against experimental human pneumococcal carriage. Mucosal Immunol. 2017, 10, 385-394. [CrossRef]

23. Malley, R.; Trzcinski, K.; Srivastava, A.; Thompson, C.M.; Anderson, P.W.; Lipsitch, M. CD4+ T cells mediate antibody-independent acquired immunity to pneumococcal colonization. Proc. Natl. Acad. Sci. USA 2005, 102, 4848-4853. [CrossRef] [PubMed]

24. Zhang, Q.; Bagrade, L.; Bernatoniene, J.; Clarke, E.; Paton, J.C.; Mitchell, T.J.; Nunez, D.A.; Finn, A. Low CD4 $\mathrm{T}$ cell immunity to pneumolysin is associated with nasopharyngeal carriage of pneumococci in children. J. Infect. Dis. 2007, 195, 1194-1202. [CrossRef] [PubMed]

25. Glennie, S.J.; Banda, D.; Gould, K.; Hinds, J.; Kamngona, A.; Everett, D.D.; Williams, N.A.; Heyderman, R.S. Defective pneumococcal-specific Th1 responses in HIV-infected adults precedes a loss of control of pneumococcal colonization. Clin. Infect. Dis. 2013, 56, 291-299. [CrossRef] [PubMed]

26. Sepako, E.; Glennie, S.J.; Jambo, K.C.; Mzinza, D.; Iwajomo, O.H.; Banda, D.; van Oosterhout, J.J.; Williams, N.A.; Gordon, S.B.; Heyderman, R.S. Incomplete recovery of pneumococcal CD4 T cell immunity after initiation of antiretroviral therapy in HIV-infected malawian adults. PLoS ONE 2014, 9, e100640. [CrossRef]

27. Diavatopoulos, D.A.; Short, K.R.; Price, J.T.; Wilksch,J.J.; Brown, L.E.; Briles, D.E.; Strugnell, R.A.; Wijburg, O.L. Influenza A virus facilitates Streptococcus pneumoniae and disease. FASEB J. 2010, 24, 1789-1798. [CrossRef]

28. Kwambana-Adams, B.; Hanson, B.; Worwui, A.; Agbla, S.; Foster-Nyarko, E.; Ceesay, F.; Ebruke, C.; Egere, U.; Zhou, Y.; Ndukum, M.; et al. Rapid replacement by non-vaccine pneumococcal serotypes may mitigate the impact of the pneumococcal conjugate vaccine on nasopharyngeal bacterial ecology. Sci.Rep. 2017, 7, 8127. [CrossRef]

29. Eisen, S.; Hayden, C.; Young, C.J.; Gilson, R.; Jungmann, E.; Jacobsen, M.C.; Poulsom, H.; Goldblatt, D.; Klein, N.J.; Baxendale, H.E. B-cell development and pneumococcal immunity in vertically acquired HIV infection. AIDS 2016, 30, 1867-1876. [CrossRef]

30. Nunes, M.C.; Madhi, S.A. Safety, immunogenicity and efficacy of pneumococcal conjugate vaccine in HIV-infected individuals. Hum. Vaccin Immunother. 2012, 8, 161-173. [CrossRef]

31. Jallow, S.; Madhi, S.A.; Madimabe, R.; Sipambo, N.; Violari, A.; Kala, U.; Petersen, K.; Naidoo, S.; Verwey, C.; Moore, D.P.; et al. Immunogenicity of 13-valent pneumococcal conjugate vaccine among children with underlying medical conditions. Vaccine 2017, 35, 4321-4329. [CrossRef]

32. Vardanjani, H.M.; Borna, H.; Ahmadi, A. Effectiveness of pneumococcal conjugate vaccination against invasive pneumococcal disease among children with and those without HIV infection: A systematic review and meta-analysis. BMC Infect. Dis. 2019, 19, 685. [CrossRef]

33. Donkor, E.S.; Annan, J.A.; Badoe, E.V.; Dayie, N.T.; Labi, A.K.; Slotved, H.C. Pneumococcal carriage among HIV infected children in Accra, Ghana. BMC Infect. Dis. 2017, 17, 133. [CrossRef] [PubMed]

34. Epping, L.; van Tonder, A.J.; Gladstone, R.A.; Bentley, S.D.; Page, A.J.; Keane, J.A.; The Global Pneumococcal Sequencing Consortium. SeroBA: Rapid high-throughput serotyping of Streptococcus pneumoniae from whole genome sequence data. Microb. Genom. 2018, 4, e000186. [CrossRef]

35. Voysey, M.; Fanshawe, T.R.; Kelly, D.F.; O’Brien, K.L.; Kandasamy, R.; Shrestha, S.; Thorson, S.; Hinds, J.; Pollard, A.J. Serotype-specific correlates of protection for pneumococcal carriage: An analysis of immunity in 19 countries. Clin. Infect. Dis. 2018, 66, 913-920. [CrossRef] [PubMed]

36. Madhi, S.A.; Koen, A.; Jose, L.; van Niekerk, N.; Adrian, P.V.; Cutland, C.; François, N.; Ruiz-Guiñazú, J.; Yarzabal, J.P.; Moreira, M.; et al. Vaccination with 10-valent pneumococcal conjugate vaccine in infants according to HIV status. Medicine 2017, 96, e5881. [CrossRef] [PubMed]

37. Silfverdal, S.A.; Skerlikova, H.; Zanova, M.; Papúchová, D.; Traskine, M.; Borys, D.; Schuerman, L. Anamnestic immune response in 3- to 4-year-old children previously immunized with 10-valent pneumococcal nontypeable Haemophilus influenzae protein D conjugate vaccine as 2-dose or 3-dose priming and a booster dose in the first year of life. Pediatr. Infect. Dis. J. 2011, 30, e155-e163. [CrossRef]

38. Prymula, R.; Habib, A.; François, N.; Borys, D.; Schuerman, L. Immunological memory and nasopharyngeal carriage in 4-year-old children previously primed and boosted with 10-valent pneumococcal non-typeable 
Haemophilus influenzae protein D conjugate vaccine (PHiD-CV) with or without concomitant prophylactic paracetamol. Vaccine 2013, 31, 2080-2088. [CrossRef]

39. Wysocki, J.; Brzostek, J.; Konior, R.; Panzer, F.G.; François, N.A.; Ravula, S.M.; Kolhe, D.A.; Song, Y.; Dieussaert, I.; Schuerman, L.; et al. Antibody persistence and immunologic memory in children vaccinated with 4 doses of pneumococcal conjugate vaccines: Results from 2 long-term follow-up studies. Hum. Vaccin. Immunother. 2017, 13, 661-675. [CrossRef]

40. Cohen, R.; Varon, E.; Béchet, S.; Bonacorsi, S.; Levy, C. Comparative impact of pneumococcal conjugate vaccines on pneumococcal meningitis according to underlying conditions. Vaccine 2016, 34, 4850-4856. [CrossRef]

41. Yildirim, I.; Shea, K.M.; Little, B.A.; Silverio, A.L.; Pelton, S.I. Vaccination, underlying comorbidities, and risk of invasive pneumococcal disease. Pediatrics 2015, 135, 495-503. [CrossRef]

42. Levy, C.; Varon, E.; Ouldali, N.; Béchet, S.; Bonacorsi, S.; Cohen, R. Changes in invasive pneumococcal disease spectrum after 13-valent pneumococcal conjugate vaccine implementation. Clin. Infect. Dis. 2020, 70, 446-454. [CrossRef]

43. Ladhani, N.S.; Collins, S.; Djennad, A.; Sheppard, L.C.; Borrow, R.; Fry, K.N.; Andrews, J.N.; Miller, E.; Ramsay, E.M. Rapid increase in non-vaccine serotypes causing invasive pneumococcal disease in England and Wales, 2000-2017: A prospective national observational cohort study. Lancet Infect. Dis. 2018, 18, 441-451. [CrossRef]

44. Vinuesa, C.G.; Cook, M.C. The molecular basis of lymphoid architecture and B cell responses: Implications for immunodeficiency and immunopathology. Curr. Mol. Med. 2001, 1, 689-725. [CrossRef] [PubMed]

45. Chiodi, F. Pneumococcal vaccination of HIV-infected young adults is an important global priority. AIDS 2016, 30, 1991-1993. [CrossRef] [PubMed]

46. MacLennan, I.C.; Bazin, H.; Chassoux, D.; Gray, D.; Lortan, J. Comparative analysis of the development of B cells in marginal zones and follicles. Adv. Exp. Med. Biol. 1985, 186, 139-144. [PubMed]

47. Gauvin, J.; Chagnon-Choquet, J.; Poudrier, J.; Roger, M.; Montreal primary HIV infection and slow progressor cohorts. Fluctuations in blood marginal zone b-cell frequencies may reflect migratory patterns associated with HIV-1 disease progression status. PLoS ONE 2016, 11, e0155868. [CrossRef] [PubMed]

48. Amu, S.; Ruffin, N.; Rethi, B.; Chiodi, F. Impairment of B cell function during HIV-1 infection. AIDS 2013, 27, 2323-2334. [CrossRef]

49. Bekele, Y.; Lemma, M.; Bobosha, K.; Yibeltal, D.; Nasi, A.; Gebre, M.; Nilsson, A.; Aseffa, A.; Howe, R.; Chiodi, F. Homing defects of B cells in HIV-1 infected children impair vaccination responses. Vaccine 2019, 37, 2348-2355. [CrossRef]

50. Jochems, S.P.; Marcon, F.; Carniel, B.F.; Holloway, M.; Mitsi, E.; Smith, E.; Gritzfeld, J.F.; Solórzano, C.; Reiné, J.; Pojar, S.; et al. Inflammation induced by influenza virus impairs human innate immune control of pneumococcus. Nat. Immunol. 2018, 19, 1299-1308. [CrossRef]

51. Madhi, S.A.; Kuwanda, L.; Cutland, C.; Holm, A.; Kayhty, H.; Klugman, K.P. Quantitative and qualitative antibody response to pneumococcal conjugate vaccine among African human immunodeficiency virus-infected and uninfected children. Pediatr. Infect. Dis. J. 2005, 24, 410-416. [CrossRef]

52. Spoulou, V.I.; Tsoumas, D.L.; Papaevangelou, V.G.; Mostrou, G.I.; Theodoridou, M.C. Immunogenicity and immunological memory induced by a 7-valent pneumococcal CRM197 conjugate vaccine in symptomatic HIV-1 infected children. Vaccine 2005, 23, 5289-5293. [CrossRef]

53. Mubarak, A.; Ahmed, M.S.; Upile, N.; Vaughan, C.; Xie, C.; Sharma, R.; Acar, P.; McCormick, M.S.; Paton, J.C.; Mitchell, T.; et al. A dynamic relationship between mucosal T helper type 17 and regulatory T-cell populations in nasopharynx evolves with age and associates with the clearance of pneumococcal carriage in humans. Clin. Microbiol. Infect. 2016, 22, 736. [CrossRef] [PubMed]

54. WHO Training Manual for Enzyme Linked Immunosorbent Assay for the Quantitation of Streptococcus Pneumoniae Serotype Specific IgG (Pn PS ELISA). (007sp Version). 2000. Available online: https://www. vaccine.uab.edu/uploads/mdocs/ELISAProtocol(007sp).pdf (accessed on 19 May 2017).

55. CDC. Identification and Characterization of Streptococcus Pneumoniae. 2016. Available online: https://www. cdc.gov/meningitis/lab-manual/chpt08-id-characterization-streppneumo.html (accessed on 5 July 2018).

56. Li, H.; Durbin, R. Fast and accurate short read alignment with Burrows-Wheeler transform. Bioinformatics 2009, 25, 1754-1760. [CrossRef] [PubMed] 
57. Mikheenko, A.; Prjibelski, A.; Saveliev, V.; Antipov, D.; Gurevich, A. Versatile genome assembly evaluation with QUAST-LG. Bioinformatics 2018, 34, i142-i150. [CrossRef] [PubMed]

58. Li, H.; Handsaker, B.; Wysoker, A.; Fennell, T.; Ruan, J.; Homer, N.; Marth, G.; Abecasis, G.; Durbin, R. The sequence alignment/map format and samtools. Bioinformatics 2009, 25, 2078-2079. [CrossRef] [PubMed]

59. Nurk, S.; Bankevich, A.; Antipov, D.; Gurevich, A.A.; Korobeynikov, A.; Lapidus, A.; Prjibelski, A.D.; Pyshkin, A.; Sirotkin, A.; Sirotkin, Y.; et al. Assembling single-cell genomes and mini-metagenomes from chimeric MDA products. J. Comput. Biol. 2013, 20, 714-737. [CrossRef] [PubMed]

60. Bolger, A.M.; Lohse, M.; Usadel, B. Trimmomatic: A flexible trimmer for illumina sequence data. Bioinformatics 2014, 30, 2114-2120. [CrossRef] [PubMed]

(C) 2020 by the authors. Licensee MDPI, Basel, Switzerland. This article is an open access article distributed under the terms and conditions of the Creative Commons Attribution (CC BY) license (http://creativecommons.org/licenses/by/4.0/). 